\title{
Aproximación Intuitiva a la Aleatoriedad, el caso de Alumnos de 13 y 14 años de un Liceo Municipal
}

\author{
Intuitive Approach to Randomness, the Case of 14 and 14-year-old \\ Students of a Municipal High School
}

\author{
Teresita Méndez Olave* \\ Ismenia Guzmán Retamal**
}

\begin{abstract}
Resumen
Este artículo da cuenta de las interacciones observadas con alumnos de 13 y 14 años, frente a una secuencia didáctica sobre aleatoriedad y certeza. Utilizamos como medio material imágenes fotográficas las que nos permitieron identificar concepciones de los alumnos sobre aleatoriedad en su estatus paramatemático, es decir, las nociones funcionando como herramientas para predecir sucesos. Nos basamos en las nociones de contrato didáctico, medio didáctico y devolución de la teoría de situaciones didácticas, para concebir las situaciones, ponerlas en práctica y posteriormente analizar las producciones de los alumnos. La metodología de investigación que adoptamos es cualitativa, siguiendo las fases de análisis a priori, experimentación y análisis de resultados. Uno de los resultados importantes da cuenta de que la mayoría de los alumnos han asignado significados subjetivos a los fenómenos aleatorios contemplados en las situaciones, lo cual deja en evidencia que los alumnos no logran identificar el suceso aleatorio contemplado en sus historias.
\end{abstract}

Palabras-clave: Aleatoriedad. Imágenes. Contrato Didáctico. Medio Didáctico. Devolución.

\begin{abstract}
The article reports on the careful examination of the interactions in students aged 13 and 14 years old when dealing with a teaching sequence about randomness and certainty. We use photographic images as the material medium that enabled us to identify students' conceptions of randomness in the "paramathematician" status; that is to say, the notions functions as tools to predict events. We rely on the notion of a didactic contract, didactic means, and the returning of the theory of didactic situations to design situations, implement them and, then, analyze the students' productions. The research methodology adopted was the qualitative analysis in ongoing phases, such as analysis a priori, experimentation, and analysis of results. Through this research arises, among other things that most students assigned to the random phenomena, subjective meanings stating clearly that they did not accomplish to identify the random event referred to in their own stories.
\end{abstract}

Keywords: Randomness. Images. Didactic contract. Didactic means. Return.

\section{Introducción}

\footnotetext{
* Estudiante del Doctorado en Educación Matemática de la Universidad de Los Lagos (ULAGOS). Académica de la Universidad Metropolitana de Ciencias de la Educación (UMCE), Santiago, Chile. Dirección Postal: Luis Trejos \# 2052, sector Rauquén, CP 3343666, Curicó, Chile. E- mail: teresita.mendez@umce.cl. tetemenz@yahoo.es

** Doctora en Didáctica de las Matemáticas por la Universidad Louis Pasteur (ULP). Profesora del Departamento de Ciencias Exactas de la Universidad de los Lagos (ULAGOS), Santiago, Chile. Dirección Postal: Avda. República 517, barrio República, CP8370341, Santiago, Chile. E-mail: ismenia.guzman@ulagos.cl
} 
Realizamos una primera exploración clínica observando a 4 niños de entre 10 y 12 años (dos de 10 años, uno de once y una de doce años). Les presentamos imágenes fotográficas a través de las cuales se les pidió escribir historias de futuro. Se les propuso además una escala del 1 al 9 para que eligieran y justificarán la posibilidad de ocurrencia de su historia. El 1 significaba imposible y el 9 absolutamente posible. Los resultados de esta experiencia se comunicaron en el reporte: Acercamientos a la impredecibilidad en la enseñanza obligatoria, Méndez y Díaz (2014).

En este artículo profundizamos este estudio considerando un marco teórico metodológico sustentado en la Teoría de Situaciones Didácticas, lo que nos ha permitido establecer nuevas relaciones entra las variables didácticas en juego. Además hemos enriquecido las situaciones y las aplicamos a un $8^{\circ}$ año de la educación obligatoria con alumnos de 13 y 14 años, lo que nos ha dado luces para prever nuevas categorías de análisis.

Desde la perspectiva de la teoría de situaciones, analizamos las producciones escritas de los alumnos y sus aportes en las puestas en común que se orquestan en distintos momentos de la clase observada.

\section{Antecedentes y problemática}

Actualmente los currículos escolares de matemática se organizan por áreas de conocimiento, una de ellas el estudio de nociones de la probabilidad, considerándola como un tipo de pensamiento matemático a desarrollar en los ciudadanos, en la educación obligatoria. En Chile, Colombia y Uruguay, las orientaciones didácticas para el ciclo de primaria, establecidas en los programas de estudio del Mineduc (2012), en los Lineamientos curriculares colombianos (1998) y en el Programa de Educación Inicial y Primaria (2009) de Uruguay, proponen desarrollar una aproximación intuitiva de la probabilidad que comienza entre los 9 y 11 años, utilizando enunciados de certidumbre e incertidumbre asociados a las expresiones: seguro, posible e imposible, del lenguaje natural, con el objeto de que el alumno(a) decida que palabra asocia al enunciado.

Se percibe en estas propuestas un efecto Topaze, Brousseau (2004), lo que significa que se sugiere una respuesta disimuladamente, puesto que para el alumno resulta cada vez más transparente y fácil responder lo que se espera, desvirtuando así el problema inicial, lo que hace desaparecer totalmente el conocimiento previsto. 
En otro nivel de enseñanza, entre 10 y 11 años, el currículo sugiere la experimentación de sucesos aleatorios como lanzamiento de monedas, dados y otros artefactos convencionales a través de los cuales se pone en evidencia la influencia del azar.

Alrededor de los 12 - 13 años el currículo propone el enfoque clásico, mediante enunciados sobre juegos aleatorios que exigen la identificación de casos favorables y posibles y el cociente entre ellos para calcular su probabilidad. De este modo cobra relevancia la regla de Laplace, Meyer (1986), algoritmo que permite calcular la probabilidad de sucesos equiprobables y de espacio muestral finito.

En las perspectivas curriculares mencionadas los experimentos aleatorios dan lugar al enfoque frecuencial de la probabilidad, cuyo propósito es asociar la tendencia de la estabilización de la frecuencia relativa a la probabilidad (teórica) del suceso, cuando el experimento se repite muchas veces bajo las mismas condiciones. Sánchez y Valdez (2013) citan a Konold et al. (2011), quienes analizan las consecuencias al introducir ambos enfoques, estudiando el pensamiento de una joven de $8^{\circ}$ grado (14 años) con conocimientos iniciales de probabilidad, los que le permitían realizar cálculos de probabilidad frecuencial y teórica, Konold et al. concluyen que ella tiene serios obstáculos para vincular las nociones de probabilidad teórica con la experimental.

Por otra parte Pfannkuch, Wild y Parsonage (2012) aportan nuevos antecedentes sobre la investigación de Konold et al. (2011): la niña en cuestión cree que todos los problemas de probabilidades podrían ser resueltos mediante una formula y que el propósito de los experimentos consiste simplemente en corroborar los resultados teóricos, porque ella cree que la probabilidad experimental es la verdadera probabilidad, argumentando que eso es lo que sucede en la práctica. Estos hallazgos son corroborados en la práctica pedagógica habitual y en distintos niveles formativos, primaria secundaria y terciaria.

Con relación a la investigación de Konold, Sánchez y Valdez (2013) afirman que se constata la dificultad de los estudiantes de esa edad para entender la conexión entre las nociones de probabilidad experimental y clásica lo que muestra que la Ley de los grandes números les resultará más complicada de comprender.

Respecto de la enseñanza de la probabilidad, Konold et al. (2011) sostienen que se debería plantear problemas que no pudieran ser resueltos por la vía teórica con tareas que soliciten estimar probabilidad mediante experimentos. También sostienen que centrarse solo en un enfoque de la probabilidad limita el pensamiento de los alumnos, lo que no permitirá contribuir a la construcción de relaciones entre la probabilidad y la inferencia. 
Por otra parte la lectura de las orientaciones didácticas de los currículos deja en evidencia al menos dos fenómenos:

- Una visión reducida del azar y la probabilidad al encasillar los problemas al ámbito de los sucesos equiprobables con espacio muestral finito y discreto.

- La recolección y organización de datos obtenidos en juegos de azar no permiten caracterizar la naturaleza aleatoria de los problemas ni tampoco reconocer otras dimensiones de esta noción.

Desde nuestro punto de vista estos fenómenos son un obstáculo para la comprensión y el reconocimiento de la aleatoriedad, ya que los enunciados propuestos dificultan la emergencia de respuestas asociadas a procesos cognitivos que involucren acciones, manipulaciones y análisis para la toma decisiones.

Al respecto Batanero y Serrano (1995) señalan que la noción de aleatoriedad junto con la idea de probabilidad son el punto de partida del cálculo de probabilidad y las expresiones relacionadas con la aleatoriedad que aparecen en el lenguaje corriente y en los textos de estudio producen dificultades de comprensión en los estudiantes ya que estas expresiones no dan cuenta claramente de su significado.

En nuestro estudio analizamos las Bases Curriculares y los programas de estudio de quinto a octavo básico del currículo chileno, Mineduc (2012), y constatamos que la noción de aleatoriedad no está considerada como un objeto de enseñanza ya que se enfatiza la clasificación de las situaciones en situaciones posibles, seguras e imposibles y no se consideran situaciones que soliciten a los alumnos(as) tomar decisiones. A nuestro juicio la noción de aleatoriedad queda invisible para los actores de la relación didáctica. Es decir no se describe, no se define ni se destacan sus propiedades.

Por otra parte Azcárate, Cardeñoso y Porlán (1998, p.86) plantean que: "la aleatoriedad siendo el núcleo central en la construcción del pensamiento probabilístico es considerada como un concepto obvio sin que su significado sea analizado en profundidad". En sus investigaciones sobre concepciones de aleatoriedad de un grupo de estudiantes de pedagogía concluyen que estas concepciones pueden llegar a ser obstáculo para la comprensión de la naturaleza probabilística de ciertos aspectos de la realidad.

Konold et al. (1991, apud. Azcárate; Cardeñoso; Porlán, 1998, p.86) señalan que "la noción de aleatoriedad es ambigua y compleja, pero entendemos que las variantes del concepto son, sin embargo, el corazón del pensamiento probabilístico y estadístico”.

Burrill y Biehler (2011) y Konold et al. (2007 apud. BIEHLER; PRATT, 2012) se refieren al enfoque de la probabilidad clásica, ejemplificada con la utilización de monedas, 
ruletas y dados. Ellos sostienen que este enfoque no da cuenta de cómo la probabilidad es utilizada profesionalmente para tomar decisiones y que las aplicaciones profesionales dan mucha más relevancia a las probabilidades que se pueden estimar en términos frecuenciales o subjetivos.

También Eicher y Vogel (2012) han encontrado que estudiantes sin estudios de probabilidad dan sentido a situaciones donde el espacio muestral no es contable. Según sus resultados los estudiantes muestran niveles cognitivos situacionalmente provocados por una tarea específica lo que influye de manera importante en la comprensión personal de los fenómenos aleatorios y en el desarrollo del pensamiento probabilístico.

Boero et al. (2009) utilizan la noción de campo de experiencia para proponer e implementar una secuencia didáctica centrada en la aproximación al pensamiento probabilístico. Ellos utilizan contextos accesibles a los estudiantes considerando el domino de los fenómenos aleatorios como un campo de experiencias y no como una mera colección de ejercicios relacionados con la probabilidad. Ellos privilegian actividades argumentativas en clases que podrían producir progresos significativos en algunos aspectos cruciales del pensamiento probabilístico en el conocimiento de los estudiantes.

Todos estos antecedentes ponen en evidencia las limitaciones de las decisiones curriculares, la reducción de los contextos de presentación de esta noción para la comprensión de la realidad y las debilidades de las orientaciones curriculares, lo que nos conduce a plantear las siguientes preguntas de investigación:

- ¿Qué actividades podrían romper el esquema tradicional de enseñanza de la probabilidad, en la educación primaria, permitiendo una aproximación intuitiva a la comprensión de la incertidumbre?

- ¿Qué actividades estarían en la zona de experiencias reales de los alumnos de 13 a 14 años, para favorecer la comprensión de los fenómenos aleatorios?

Entendemos por comprensión de los fenómenos aleatorios la toma de conciencia de las características impredecibles de un suceso, las circunstancias que podrían afectarlo según las experiencias reales de los sujetos.

Nuestro propósito es que las situaciones evidencien las intuiciones de los alumnos de 13 a 14 años y nos permitan identificar categorías para analizar las concepciones de niños y clasificar su pensamiento aleatorio.

\section{Marco teórico}


Para nuestra investigación nos hemos apoyado en algunos conceptos de la Teoría de Situaciones Didácticas (TSD) de Guy Brousseau, la que considera centrales las situaciones que privilegian las interacciones de los alumnos con una actividad matemática.

Esta teoría se centra en la relación didáctica en clases, por ello los conceptos de contrato didáctico y medio son esenciales; Brousseau (2004, p.61) plantea que una de las primeras tareas que el contrato didáctico le propone al profesor es crear las condiciones para el desarrollo de la relación didáctica en clases. El afirma: "El profesor crea las condiciones suficientes para la apropiación de conocimientos, y él debe reconocer esta apropiación cuando ella se produce".

Junto a lo anterior, la noción de medio se concibe como un "conjunto de circunstancias exteriores" que confrontan al alumno provocándole desequilibrios cognitivos o adaptaciones al medio. Una condición del medio, prevista por Brousseau es que resista a la interpretación inmediata del alumno. En este sentido "el medio, juega un rol central en el aprendizaje como causa de adaptaciones y en la enseñanza como referencia y objeto epistemológico" (BROUSSEAU, 1988, p.321). También el medio juega como un sistema antagonista que debe favorecer el cuestionamiento del objeto matemático, recortarlo y vincularlo con otros saberes.

En la relación didáctica frente a las dificultades de los alumnos en clases, con frecuencia será necesario que el profesor intervenga el medio, lo que afectará al contrato didáctico produciendo una modificación o cambio de contrato en relación a la tarea del alumno. Teóricamente hablamos de cambio o una ruptura de contrato, estas rupturas pueden ser positivas o negativas. Las primeras respaldan la apropiación de aprendizajes y las segundas colocan al profesor en posición de restaurar la relación didáctica interviniendo el medio de modo de garantizar la actividad matemática autónoma del alumno. Uno de los roles del medio es permitir la evolución de la situación de aprendizaje mediante la búsqueda de nuevos contratos, este es el medio que se conoce como medio adidáctico, ya que favorece la actividad matemática autónoma del alumno.

Por su parte, Perrin-Glorian y Hersant (2003, p.219) aseguran que:

[...] es el medio el que caracteriza a la situación adidáctica, si el medio cambia la situación cambia. En efecto el sujeto puede ser visto como un sistema de conocimientos que interactúa con un medio antagonista; el medio reacciona a las acciones del sujeto por retroacciones que el sujeto interpreta con sus conocimientos. El aprendizaje se produce mediante la interpretación que el alumno realiza de los efectos de sus acciones sobre el medio y por la adaptación al medio. 
En esta perspectiva teórica se requiere situar a los alumnos frente a situaciones de aprendizaje, que los desafíen y les provoquen adaptaciones adecuadas en vista de la situación propuesta. Brousseau (1998, p.316-317) afirma:

[...] se puede vislumbrar una familia de situaciones donde una noción funcione como un conocimiento (situaciones de acción), una familia de situaciones donde ella figure como un saber (por ejemplo situaciones de validación), una familia de situaciones donde aparece una necesidad de conocimientos y de la posibilidad de satisfacerla por la comunicación del saber correspondiente. Estas diferentes formas de funcionamiento, de los conocimientos, determinan diferentes niveles de control utilizados por un jugador en una situación.

Perrin-Glorian y Hersant sostienen que las situaciones didácticas (de acción, formulación y validación) están definidas por tipos diferentes de interacción del sujeto con el medio.

Para la acción se tiene una interacción directa con el medio (efectivo o evocado), para la formulación la interacción [...] ella necesita intercambios de información entre dos sujetos que cooperan en una tarea común donde aparece un saber y para la validación, ella necesita intercambios de afirmaciones sobre el medio y a los saberes enunciados. (PERRIN-GLORIAN Y HERSANT, 2003, p. 220).

Un proceso importante en la enseñanza es el proceso de devolución, el cual se concibe como la responsabilidad que el profesor transfiere al alumno con el fin de que éste busque caminos de solución a los problemas o ejercicios que se le proponen pero de los que él ignora la respuesta. Brousseau (1988, p.325) define "la devolución como el acto por el cual el profesor logra que el alumno acepte la responsabilidad de buscar en forma autónoma una solución de una situación de aprendizaje (adidáctica) o de un problema y acepte el mismo las consecuencias de esta transferencia”.

En el seno de una clase las nociones de contrato didáctico, medio y devolución se materializan en el momento en que el profesor solicita a los alumnos realizar una actividad matemática particular que ha preparado para un curso determinado. En este momento el profesor hace devolución al alumno de un problema y al mismo tiempo se determina un conjunto de obligaciones que implica la responsabilidad del alumno de trabajar, individualmente (o colectiva según el contrato) de manera que se adapte a las retroacciones del medio.

En general desde el punto de vista de la TSD, la actividad propuesta se compone de un contrato didáctico y un medio de aprendizaje, antagonista al alumno en el sentido de que las acciones e interacciones del alumno con el medio sean motivadas por razones intelectuales y por tanto epistemológicas. El medio cuestiona las decisiones del alumno como consecuencia del resultado de sus acciones; el medio no permite que el alumno realice una interpretación inmediata y trivial de la situación. 
Durante este proceso de interacción, alumno-medio, el rol del profesor es favorecer el trabajo autónomo del alumno a través de retroalimentaciones formuladas mediante preguntas que eviten caer en el efecto Topaze u otros fenómenos didácticos que desvirtúen el aprendizaje esperado. Estas interacciones del profesor son devoluciones, necesarias para conservar la relación didáctica con autonomía en la actividad matemática del alumno y lograr el aprendizaje.

En nuestra investigación utilizamos imágenes frente a las cuales el contrato didáctico solicitaba escribir historias que podrían ser interpretadas como predicciones de sucesos aleatorios; en este contrato el medio está representado por las imágenes.

Durante la puesta en práctica de la situación el proceso de devolución fue marcando los cambios de contrato. Al comienzo de la clase la profesora solicita a los alumnos escribir historias de futuro sobre el contenido de las imágenes (la tarea), luego intercambio en parejas sobre las historias y en la puesta en común se comentan las historias y se pone en evidencia el carácter de incertidumbre o certidumbre de las historias relatadas y con ello surge la noción intuitiva de aleatoriedad.

\section{Metodología de investigación}

La metodología de investigación es cualitativa, utilizamos algunas fases de la metodología ingeniería didáctica de investigación: análisis a priori - experimentación en clases - análisis de la experiencia y conclusiones.

El diseño de las situaciones de incertidumbre se apoya en imágenes, algunas seleccionadas de la WEB otras son imágenes personales. Estas imágenes forman parte del medio adidáctico. Suponemos que ellas permiten poner en funcionamiento las creencias e intuiciones de los estudiantes para describir elementos de aleatoriedad y podrían favorecer el desarrollo de estrategias que activan mecanismos de comprensión e interpretación de la incertidumbre en cada estudiante.

La muestra consta de 31 alumnos de $8^{\circ}$ básico, entre 13 y 14 años de un colegio municipal de la región del Maule, Chile.

Las informaciones recogidas son analizadas, considerando las nociones de la Teoría de Situaciones Didácticas, contrato didáctico, medio didáctico y proceso de devolución.

\subsection{Análisis a priori}


La situación planteada en esta investigación solicita a los alumnos escribir historias con relación a sucesos aleatorios para estimar una posibilidad de ocurrencia.

El contrato didáctico pide a los alumnos escribir historias sobre acontecimientos futuros frente a imágenes que se les presentan, el medio adidáctico son las imágenes, consideradas como un recurso dinamizador del aprendizaje que puede facilitar el descubrimiento de nociones complejas (APARICI; GARCÍA, 1989). Suponemos que en las producciones de los alumnos, la noción de aleatoriedad aparecerá con estatus paramatemático (herramienta) y expresada en lenguaje cotidiano e informal.

A continuación, las imágenes utilizadas (Figuras 1, 2, 3 y 4).

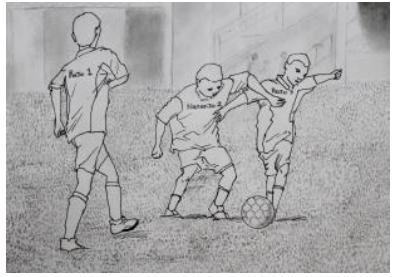

Figura 1 La jugada de futbol

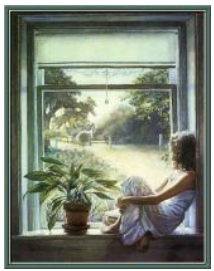

Figura 2 La niña

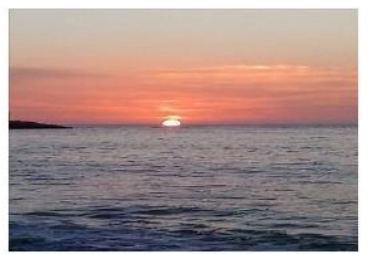

Figura 3 Plantación de porotos

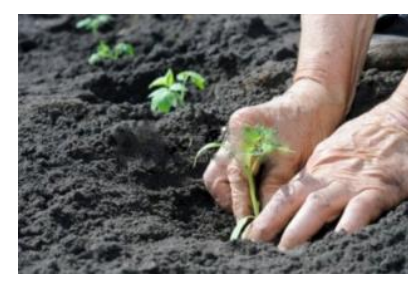

Figura 4 La puesta de sol

El Cuadro 1 muestra posibles historias de los alumnos frente a las imágenes:

\begin{tabular}{|l|l|l|l|}
\hline La jugada de fútbol & La niña en la ventana & Plantación de porotos & La puesta de sol \\
\hline $\begin{array}{l}\text { En el fútbol puede } \\
\text { pasar cualquier cosa. }\end{array}$ & $\begin{array}{l}\text { La niña está descansando } \\
\text { después de un arduo día de } \\
\text { trabajo. }\end{array}$ & $\begin{array}{l}\text { En tres meses más todas las } \\
\text { plantas estarán crecidas y del } \\
\text { mismo tamaño. }\end{array}$ & $\begin{array}{l}\text { En dos horas más } \\
\text { estará de noche y la } \\
\text { playa oscura. }\end{array}$ \\
$\begin{array}{l}\text { No se puede saber con } \\
\text { seguridad lo que } \\
\text { ocurrirá hasta que la } \\
\text { jugada se produzca. }\end{array}$ & $\begin{array}{l}\text { La niña espera la llegada de } \\
\text { alguien que aparecerá frente } \\
\text { a ventona algunas plantas } \\
\text { crecerán y otras morirán por } \\
\text { distintos factores, como los } \\
\text { climáticos o porque han sido } \\
\text { pisoteadas o arrancadas. }\end{array}$ & \\
$\begin{array}{l}\text { No se puede saber lo } \\
\text { que ocurrirá porque } \\
\text { pueden ocurrir muchas } \\
\text { cosas. }\end{array}$ & $\begin{array}{l}\text { No se puede saber lo que la niña en la ventana, } \\
\text { pueden ser muchas cosas. }\end{array}$ & & \\
\hline
\end{tabular}

Cuadro 1 - Predicciones sobre las historias escritas por los alumnos

Este cuadro nos ha permitido prever categorías de análisis de las producciones de los estudiantes que dejarán en evidencia la concepción intuitiva de aleatoriedad.

Para cada categoría definimos los siguientes códigos: $R A$ : Reconoce la aleatoriedad; $S S$ : Suposición subjetiva; $S V$ : Suposición desde lo visual; $S E$ : Suposición desde la experiencia y $S F$ : Suposición desde la fantasía.

Categoría $1(R A)$ : elabora historias de futuro asignando nivel de posibilidad posible, poco posible o muy posible. En sus explicaciones el sujeto se abre a considerar otras historias sobre el mismo suceso. La noción de aleatoriedad tiene estatus paramatemático porque la noción es 
implícita y funciona como herramienta para explicar la posibilidad de un suceso, esto se evidencia en explicaciones como: en el futbol puede pasar cualquier cosa.

Categoría 2 (SS): agrega suposiciones subjetivas sobre lo que puede suceder en el futuro y asigna seguridad de ocurrencia a su historia. Queda en evidencia en estas concepciones el no reconocimiento de la incertidumbre ya que las explicaciones relacionan la suposición con la seguridad de ocurrencia. Por ejemplo, la historia: El niño de naranjo que va con el balón cae al suelo y el partido es detenido por un instante, es seguro que sucederá.

Categoría $3(S V)$ : formula historias de futuro asignando seguridad de ocurrencia desde lo que visualiza en la imágen. En este caso el alumno no reconoce la influencia del azar en el suceso que relata. Por ejemplo se ve (en la imagen) que al niño de rojo le van a quita la pelota.

Categoría $4(S E)$ : formula historias de futuro asignando seguridad de ocurrencia apoyándose en su experiencia frente a situaciones similares. En este caso queda en evidencia el no reconocimiento de la aleatoriedad. Por ejemplo: al niño de rojo le van a quitar la pelota porque siempre pasa en jugadas como esa.

Categoría $5(S F)$ : formula historias de futuro fantasiosas y entonces asigna el nivel imposible. En este caso tampoco se reconoce la aleatoriedad.

\subsection{Experimentación: la gestión de la clase}

En la metodología de la clase se consideraron las etapas de: Visualización, Escritura y Puesta en Común. En los primeros minutos de la clase se deja a los alumnos visualizar el contenido de las imágenes. En seguida se les da tiempo para escribir sus historias y completar la tabla adjunta en la hoja de respuesta. Consideramos un trabajo individual para las primeras tres imágenes (más o menos 20 minutos) y para la cuarta imagen se ha previsto posteriormente un trabajo en equipo.

La profesora, comenzó su clase proyectando en la pizarra una a una las imágenes ya expuestas anteriormente (Figuras 1, 2, 3 y 4). Ella solicita a los alumnos las tres tareas siguientes.

1. Escribe en la tabla que aparece en tu hoja de respuesta, dos historias para cada imagen que según tu opinión ocurrirán en el instante siguiente.

2. Asigna una posibilidad de ocurrencia según los indicadores dados en la tabla de posibilidades siguiente: 


\begin{tabular}{|c|l|l|}
\hline código & $\begin{array}{l}\text { Posibilidad de } \\
\text { la historia } \mathrm{P}(\mathrm{H})\end{array}$ & Explicación \\
\hline & & \\
\hline A & imposible & La historia nunca sucederá. \\
\hline B & Casi imposible & La historia tiene poca posibilidad de ocurrencia \\
\hline C & Incierto. & No se puede saber con certeza si la historia ocurrirá \\
\hline D & Muy posible & Es muy posible que ocurra la historia, pero no es absolutamente seguro. \\
\hline E & seguro & Seguridad de ocurrencia de la historia. \\
\hline
\end{tabular}

Cuadro 2 - Nivel de posibilidades de las historias

3. Explica tu decisión.

Después del trabajo individual, se realiza una puesta en común con objeto de determinar el significado de las historias formuladas.

Hemos codificado por $P$ para intervenciones de la profesora y por $A$ con un subíndice la intervención de alumnos. A continuación, un extracto del protocolo en tres fases.

\section{Fase 1. Trabajo individual}

1. P: Ahora ustedes van a explicar ¿qué les pedía la tarea 1?

2. A4: hacer como una hipótesis de lo que creemos que puede pasar en el futuro.

3. P: Cuando dices hacer como una hipótesis, ¿A qué te refieres?

4. A4: Las hipótesis son como una aproximación de lo que uno ve, o sea de lo que puede pasar.

5. A5: Al crear historias, ahí uno está creando una hipótesis de lo que puede pasar a continuación.

6. A18: una hipótesis es una ..., es como una historia ficticia que uno crea a partir de algo que se imagina, es como algo que inventa uno para darse una respuesta a lo que vio y no sabe.

7. A20: No se sabe lo que va a pasar. Igual uno puede tener una idea de algo que puede venir, como algo pequeño que de una idea de lo que va a pasar.

8. P: ¿qué característica común presentan estas tres imágenes?

9. A11: que en todas se tiene que hacer historias ahí, de lo que va pasar.

10. A30: que todas tiene como hincapié pa'dar no se po una historia que va a pasar después de lo que está en la imagen.

11. A31: eso es como una pequeña escena de ..., a partir de eso uno tiene que empezar a ... crear historias.

\section{Fase 2 Trabajo Colectivo}

En esta fase la profesora $P$ propone comentar las historias que escribieron sobre la jugada de futbol, con el fin de que los alumnos lleguen a concordar que todas las historias son diferentes.

Su propósito es introducir la noción de incertidumbre como resultante de un suceso aleatorio.

P: Formen grupos de cuatro compañeros y comenten sus historias sobre la jugada de futbol Esto comienza en el minuto 48 de la clase y se extendió más o menos 5 minutos.

12. $\quad P:$ ¿Encontraron algunas historias diferentes? 
13. Siii!! Constentan algunos alumnos,

14. P. ¿Cuales?

15. A7 : El niñito de rojo (que esta de espalda) iba a hacer una barrida y le quita la pelota

16. A10 : el niño de rojo (a la derecha) iba a meter el gol

17. A4: el niño de naranja se la quitaba el niño de rojo

18. P: ¿Hubo grupos en qué todas las historias eran iguales?

19. Muchos: nooooo!!

20. P: ¿cuántas historias aparecieron en cada grupo?

21. A4: en mi grupo 6 historias diferentes (yo tres, una compañera dos y la otra una.)

22. P: ¿Habrían otras hipótesis en relación con esta imagen?

23. A13 Que algunas personas estuvieron en el partido y tal vez saben lo que pasó.

La clase continúa con la cuarta imagen - La puesta del sol. Minuto 65 más o menos.

Fase 3

P proyecta en la pizarra la cuarta imagen, diciendo: escriban en común dos historias sobre lo que sucederá en la playa dos horas más tarde y elijan una posibilidad de la tabla que tienen en su hoja de respuesta. Ella espera que los alumnos se den cuenta de que en este caso solo se puede escribir una historia a diferencia de lo que ocurre con las imágenes anteriores. Su propósito es introducir la noción de suceso determinista, como resultante de un suceso seguro. Esta actividad se extendió por 10 minutos màs o menos. A continuación un extracto del protocolo:

24. P : ahora escuchemos las hipótesis de cada grupo

25. G1 : nosotros: que se oscurecía, que se escondía el sol o que se iba a hacer de noche

26. G2 : se oscurece; sube la marea

27. G3: que podíamos creer que podía haber un tsunami.

28. G4: que se apague el sol

29. G5: Se hacía de noche

30. P: Para cada hipótesis qué posibilidades asignaron

31. G1 y G2: seguro que va a pasar

32. P: $G 3$, ¿qué posibilidad le asignaron a que hubiera un tsunami?

33. G3 puede que suceda

34. P: G4 ¿qué posibilidad le dan a que se apague el sol?

35. G4 eh!.. que en la playa iba a subir la marea porque es la luz de la luna ...

Sigue la clase y P les solicita comparar las historias de la puesta de sol con las historias escritas sobre las otras imágenes.

36. P: ¿Qué han encontrado? ¿han podido inventar varias hipótesis tal como con las otras imágenes? (Con esta pregunta ella espera un No, pero sucede lo contrario) 37. A14: Si!

38. ¿incluso podrían ser más!, varias voces.

Observamos que los alumnos no responden como $\mathrm{P}$ esperaba. $\mathrm{P}$ se ve obligada a retomar el sentido de la pregunta anterior y la clase continúa como sigue:

39. P: ¿en cuál de las imágenes, se podrían inventar más historias? 
40. A15: en la del partido de fútbol

41. P: ¿En cuál no se pueden inventar tantas historias?

42. A25: En el atardecer

43. P: ¿Qué posibilidad de ocurrencia asignan a estas historias de la Puesta de sol?

44. A25 y varios: que va a suceder

45. P: Comparemos las hipótesis de la puesta de Sol con la jugada de fútbol: ¿qué diferencia hay entre ellas?

46. A12: Que en el partido de fútbol hay más probabilidad de que pasen muchas más cosas que en el atardecer que es obvio que se va a hacer de noche y el sol ya no va a estar.

47. A30: Por ejemplo en el atardecer son cosas que siempre ocurren y en partido de fútbol puede ser variable: se puede romper la rodilla, se puede tropezar con la pelota, con una champa de pasto.

48. P: Lo que dice A 30 ¿a qué se refiere?

49. A4: son hipótesis, posibilidades.

50. P: son hipótesis y ellas tienen posibilidades. Jóvenes, en términos de las posibilidades ¿en qué se diferencian las hipótesis de la jugada de fútbol y de la puesta de sol?

51. A13: En que la puesta de sol es más seguro, porque tiene menos posibilidad de que cambie.

52. P: Bien A13, en la puesta de sol hay posibilidad de seguridad y en la jugada de fútbol no la hay, puede que sí o puede que no ocurra.

53. A 16: claro! en la jugada de fútbol puede ser

54. A 17: eeeh.... Es que entre más posibilidades hayan, es menos seguro que ocurra y entre menos historias es más seguro que ocurra.

55. P: En resumen el trabajo con las imágenes consistió en inventar historias o hipótesis para determinar sus posibilidades de ocurrencia. Vimos que las hipótesis se pueden clasificar, se dirige a A 10 ¿qué clasificación harías tú?

56. A10: no se po, puede ser, ... es seguro que suceda, es posible que suceda,...

57. A 15: esa. No se po, hay un montón de probabilidades de lo que le pueda pasar a los porotitos en tres meses. No se po puede llover, puede que un perrito ahi se las coma.

58. A31: También puede que haya un cambio muy brusco del clima y eso le afecte a las plantas y no sea posible que su crecimiento llegue.

59. P: ¿que está diciendo A15?

60. A30 está diciendo hipótesis

61. P: Bien, él está formulando nuevas hipótesis

Fin de la Clase.

\subsection{Análisis de resultados de la experimentación}

\subsubsection{Producciones: Textos de las historias}

En el Cuadro 3 se puede observar: las categorías que definimos de acuerdo a la concepción intuitiva de aleatoriedad detectada (col 1); la frecuencia de aparición de la categoría en los textos de los alumnos (col. 2); una selección de textos, sobre la jugada de fútbol (col 3) y además explicaciones, según a la posibilidad de ocurrencia asignada por el alumno. (col.4). (cf. p. 11).

\begin{tabular}{|l|l|l|l|}
\hline Categoría & Frec. & Algunas producciones estudiantiles: Historia & $\begin{array}{l}\text { Nivel de posibilidad y } \\
\text { explicación de la decisión. }\end{array}$ \\
\hline
\end{tabular}




\begin{tabular}{|l|l|l|l|}
\hline C1 RA & 13 & $\begin{array}{l}\text { El niño que va con el balón pasa al primer } \\
\text { contrincante y el segundo rival lo tira al suelo con } \\
\text { un fuerte golpe. } \\
\text { El jugador va a esquivar a los que se la quieren } \\
\text { quitar la pelota, va a patear al arco y iigol!! }\end{array}$ & $\begin{array}{l}\text { No lo puedo saber: Puede que } \\
\text { el niño se pase a uno y el otro } \\
\text { lo derribe. } \\
\text { Posible: puede ser como no, } \\
\text { porque también se la pueden } \\
\text { quitar o lo dicho antes. }\end{array}$ \\
\hline C2 SS & 30 & $\begin{array}{l}\text { El niño de naranjo que va con el balón cae al suelo y } \\
\text { el partido es detenido por un instante. }\end{array}$ & $\begin{array}{l}\text { Seguro le cometen falta y el } \\
\text { árbitro cobra falta }\end{array}$ \\
\hline C3 SV & 11 & $\begin{array}{l}\text { Un jugador se puede caer y lesionarse un pie, o otra } \\
\text { parte del cuerpo }\end{array}$ & $\begin{array}{l}\text { Posible: por la forma en que } \\
\text { se encuentra un jugador } \\
\text { pareciera que se va a caer }\end{array}$ \\
\hline C4 SE & 3 & $\begin{array}{l}\text { El niño sigue corriendo y se le va la pelota y es } \\
\text { saque de lado }\end{array}$ & $\begin{array}{l}\text { Posible: porque casi siempre } \\
\text { ocurre eso. }\end{array}$ \\
\hline C5 SF & $\begin{array}{l}\text { El niño caerá al piso y el padre entrará, golpeará a } \\
\text { los niños que botaron a su hijo y correrá a los } \\
\text { policías, después lo atraparán y explotará porque } \\
\text { tenía una bomba en el estomago }\end{array}$ & $\begin{array}{l}\text { Imposible: porque no puede } \\
\text { explotar ni le pueden dejar } \\
\text { una bomba en el estómago } \\
\text { que explote cuando lo atrapen }\end{array}$ \\
\hline
\end{tabular}

Cuadro 3 - Síntesis de resultados historias en la jugada de futbol

Esta síntesis de resultados constata que en 13 de 57 historias, las explicaciones ponen en evidencia que la imagen de la jugada de fútbol puede originar diferentes historias, lo que significa que no se puede saber con certeza si la historia ocurrirá. Consideramos aquí una suerte de reconocimiento intuitivo de la aleatoriedad.

Explicaciones (dadas en la jugada de futbol) como: no se puede saber lo que va a pasar; (en la plantación de porotos): las plantas pueden ser arrancadas por un perro o pueden crecer normalmente, sugieren que las historias formuladas son impredecibles y su seguridad de ocurrencia es incierta. Lo que es una característica de los sucesos aleatorios.

De acuerdo a nuestras categorías de análisis (p. 10) en la jugada de fútbol se aprecia que las concepciones de los alumnos sobre aleatoriedad se distribuyen en: reconoce la aleatoriedad 13 historias, suposición subjetiva 24, suposición desde lo visual 11, suposición desde la experiencia 3 y suposición ficticia 1.

En las primeras tres imágenes propuestas en la clase, la mayoría de los alumnos formularon historias relacionadas con argumentos inferenciales subjetivos, que no les permitieron reconocer la aleatoriedad. Por ejemplo en la jugada de fútbol, un alumno escribe: el jugador de naranjo empuja al de rojo y gane la pelota, y le asigna posibilidad segura, explicando que eso pasa siempre, lo he visto varias veces en otros partidos.

\subsubsection{Puesta en común y Análisis}


En la puesta en común se distinguen tres fases: en la fase 1, constatamos que desde el principio los alumnos han comprendido la tarea, ya que las primeras explicaciones a la pregunta de la Profesora: ... ¿qué les pedía la tarea 1? Se recogen respuestas como:
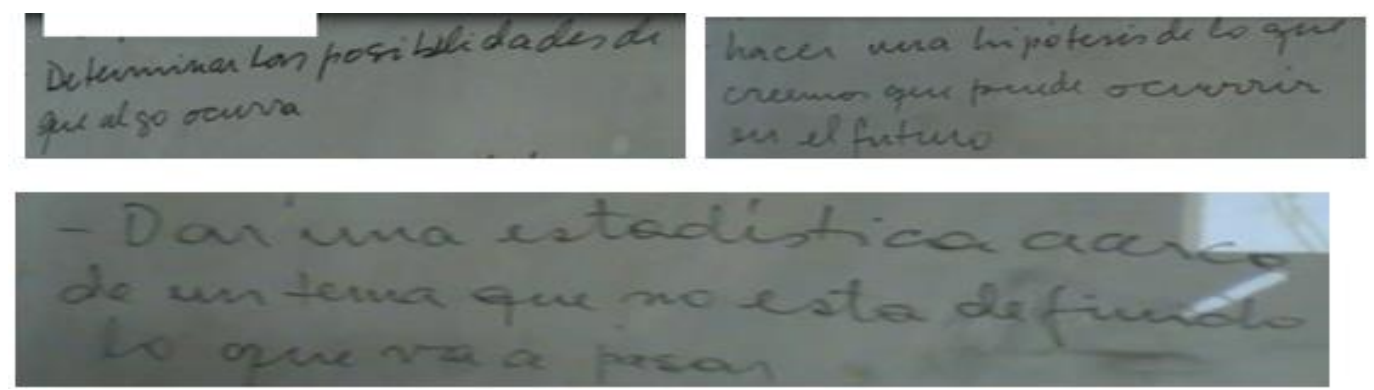

Figura 5 - Expresiones de los alumnos escritas por la profesora en el pizarrón

En esta fase se materializa la cláusula del contrato didáctico inicial de la puesta en común: explicar el significado de las historias formuladas frente a toda la clase. En estas expresiones, las historias son para los alumnos hipótesis de lo que creen que va a ocurrir y que ellas son impredecible. Esto se manifiesta en respuestas como: No se sabe lo que va a pasar, lo que creemos que puede pasar en el futuro o darse una respuesta de lo que puede venir.

Aquí el medio adidáctico son las historias, los alumnos se han dado cuenta de que pueden imaginar lo que puede suceder a futuro a partir de una imagen, (medio material) que contiene un suceso del que no se sabe lo que va a pasar, como afirma A20 en la línea 7: p. 12.

Se aprecia que las imágenes dan origen a diferentes historias que caracterizan la variabilidad impredecible del fenómeno. Interpretamos estos relatos como sucesos del espacio muestral del fenómeno aleatorio relacionado con el contenido de la imagen.

En la fase 2, se centra la atención en las historias sobre la jugada de futbol claramente hay un cambio de contrato en que la tarea ahora es identificar diferencias o coincidencias en las hipótesis formuladas a partir de esa imagen.

Las expresiones de los alumnos dejan en evidencia que desde esa imagen se pueden relatar diferentes historias o hipótesis.

Nuevamente aquí el medio adidáctico está constituido por las historias de la imagen sobre la jugada de fútbol.

En la fase 3, encontramos un contrato didáctico que tiene en cuenta dos tareas: en la tarea 1 los alumnos en grupo escriben historias sobre la imagen de la Puesta de Sol, en general formulan hipótesis de posibilidad segura, interpretamos este hecho como un suceso determinista, cuestión ya prevista en el análisis a priori. 
Pocos grupos formularon hipótesis de posibilidad incierta, como G3 en la línea 27, (p. 13) donde se lee la hipótesis ...creer que podía haber un tsunami, ellos le han asignado la posibilidad puede suceder, en la línea 33.

En la tarea 2 se solicitaba comparar las hipótesis de la puesta de sol con las que escribieron antes en el trabajo individual respecto a las otras imágenes. Frente a la pregunta formulada por la Profesora en la línea 36, observamos que los alumnos no responden a lo esperado. Claramente hay aquí una ruptura de contrato. $P$ esperaba un $n o$ y se ve obligada a retomar la actividad y plantearles una nueva pregunta, como se lee en línea 39 (P: ¿en cuál de las imágenes, se podrían inventar más historias?).

Al término de la clase, los alumnos llegan a establecer diferencias entre las hipótesis que originan un tipo de imagen y otro. Por ejemplo A30, en la línea 47 sostiene que la imagen de la La puesta de sol da origen siempre el mismo efecto (misma hipótesis), y que en La jugada de fútbol existe mayor variabilidad en la formulación de hipótesis. En el transcurso de la puesta en común, A15 en la línea 57 y A31 en la línea 58 evidencian la variabilidad en la probabilidad de que alguna de las hipótesis ocurra (p.14).

\section{Conclusiones}

En nuestra investigación elaboramos una secuencia didáctica que propuso a los alumnos trabajar en el dominio de la aleatoriedad. La implementación de la secuencia ha dejado en evidencia algunos hallazgos.

Abordamos la noción de aleatoriedad desde una aproximación intuitiva, lo que nos ha permitido acceder a escenarios didácticos no considerados en la enseñanza actual y que podrían ampliar el ámbito de estudio de la probabilidad y contribuir a superar obstáculos didácticos provocados por las decisiones curriculares actuales, en la formación del pensamiento probabilístico de los alumnos. Ideas que compartimos con los resultados de los trabajos de Konold et al. (2011 insertar en las referencias) y Sánchez y Valdez (2013), señalados en el sector de los Antecedentes (p. 3 y 4).

En las producciones escritas de algunos alumnos surgió la noción intuitiva de aleatoriedad, la hemos encontrado en los razonamientos que contenían argumentaciones analíticas, las que les permitió a los alumnos predecir otras posibilidades de ocurrencia del suceso. Otras producciones evidenciaron concepciones subjetivas de los significados que los alumnos asociaron a sucesos aleatorios. Interpretamos estas concepciones como una suerte de razonamiento argumentativo inferencial, el cual no les ha permitido a estos alumnos intuir la 
noción de aleatoriedad. Estos hallazgos se hicieron evidentes gracias a las categorías que identificamos a partir del análisis a priori que realizamos (cf. p. 10,11).

Otro de los hallazgos se refiere a los significados particulares que los alumnos dieron en relación con la aleatoriedad, los que funcionaron como concepto paramatemático, es decir los utilizaron como herramienta para comentar sus historias. Ellos aparecieron en la puesta en común desde sus experiencias personales y concepciones intuitivas.

Pensamos que el conjunto de historias describiría el espacio muestral de un suceso aleatorio no repetible por experimentación y los niveles de posibilidad los podemos interpretar como una medida cualitativa de la incertidumbre relativa a las historias.

Lo anterior contribuiría a dar significado a la noción de probabilidad como medida de incertidumbre.

En nuestra investigación, las situaciones que experimentamos consideraron tareas cuyos contextos se situaron en la zona de experiencias reales de los alumnos, por lo que se logró romper con el esquema tradicional y usual de la enseñanza de la probabilidad.

Además en los episodios destacados de la clase hemos podido constatar el funcionamiento de las nociones de contrato didáctico y medio, de las rupturas de contrato, de las características del medio y de su evolución en cada fase. La primera ruptura de contrato es positiva y la constituye la interpretación que los alumnos han dado a las historias escritas: son como hipótesis de un futuro que puede o va a ocurrir. Esta es una hipótesis y tiene la connotación de una predicción. En la evolución de la situación se produjo una ruptura de contrato negativa, cuando se discute sobre la puesta de sol, lo que alerta a la profesora a centrar la discusión y para no perder el objetivo que se propuso, que era establecer que en un fenómeno determinista solo se puede formular una hipótesis, restituye la relación didáctica formulando una nueva pregunta. Estas rupturas de contrato llevaron a los alumnos, al final de la clase, a comprender que pueden haber muchas historias sobre una misma imágen, con posibilidad de ocurrencia, posible, poco posible o muy posible, y que hay imágenes relacionadas con una sola historia, como en la puesta de sol que tienen seguridad de ocurrencia.

Claramente estas rupturas de contrato estuvieron en sintonía con la evolución del medio adidáctico, en un primer momento las imágenes constituyeron este medio, las que dieron origen a las historias pedidas en el contrato didáctico. Luego, hay un cambio de contrato cuando la tarea es pronunciarse sobre la posibilidad de ocurrencia de ellas, y en ese momento el medio lo constituyen las historias. El proceso de devolución también forma parte 
del medio puesto que están constituidas por las intervenciones del profesor, sus preguntas, y las explicaciones de los alumnos como respuestas.

Al final de la clase, la mayoría de los alumnos logra comprender la noción de aleatoriedad intuitiva. Ellos logran la convicción de la incertidumbre de las historias una vez estudiada la imagen de la puesta de sol, ya que sus historias reflejaban la certidumbre del suceso. Es decir el contrastar las posibilidades de las historias de la puesta de sol con las formuladas en relación a las otras imágenes, llevo a los alumnos a comprender la noción de incertidumbre.

Un aporte relevante de este estudio es la identificación de cinco categorías que reflejaron las concepciones intuitivas de aleatoriedad de los alumnos. Ellas cumplieron el rol de herramienta metodológica para el estudio teórico de las concepciones de los niños en su zona de experiencias reales de la incertidumbre. Esto porque las formas de razonar asociadas a la incertidumbre que especificamos en las categorías forman parte del pensamiento del hombre común y corriente desde la antiguiedad hasta nuestros tiempos. Batanero, Henry y Parzysz, (2006, p.16) citan a Jacques Bernoulli (1713/1987) quién en la introducción a la cuarta parte de Ars Conjectandi, escribió: "por siglos toda especulación acerca de eventos futuros fue inconcebible, ya que el futuro sólo pertenecía a la omnisciente y la gloria omnipotente del supremo creador”.

También el rol de las imágenes como motor de expansión discursiva de las predicciones formuladas en las historias que los estudiantes escribieron resultaron ser un medio eficaz, ellas permitieron capturar las concepciones de los alumnos sobre aleatoriedad.

Ahora nuestras preocupaciones están centradas en la necesidad de organizar un medio adidáctico que permita superar el nivel intuitivo de esta noción, en la educación primaria.

\section{Referencias}

Administración nacional de Educación Pública. 2009. Programa de Educación Inicial y Primaria. Montevideo: Rosgal. S.A.

APARICI, R.; GARCÍA, A. Imagen, vídeo y Educación. 2. ed. México. Fondo de Cultura Económica, 1989.

AZCÁRATE, P.; CARDEÑOSO, J.; PORLÁN, R. Concepciones de futuros profesores de primaria sobre la noción de aleatoriedad. Enseñanza de las Ciencias, Barcelona, v. 1 n.16, p. 85 - 97, jun., 1998.

BATANERO, C.; SERRANO, L. La aleatoriedad, sus significados e implicaciones Educativas.

Revista UNO, Barcelona, nº 5, p. 15 - 28, jul., 1995. 
BATANERO, C.; HENRY. M.; PARZYSZ, B. The nature of chance and probability. In: Jones, G. (org.) Exploring probability in school: Challenges for teaching and learning. Nueva York, Board, 2006. p. $16-43$.

BIEHLER, R.; PRATT, D. Research on the reasoning, teaching and learning of probability and uncertainty. ZDM Mathematics Education, Hamburgo, v. 44, p. 819- 823, 2012.

BOERO, P. et al. Research for innovation: a teaching Sequence on the argumentative approach to probabilistic thinking in grades $\mathrm{I}-\mathrm{V}$ and some related Basic research results. Recherches en Didactiques des Mathématique. Grenoble, v. 29, n. 1, p. 59 - 96, 2009.

BROUSSEAU, G. Théorie des situations Didactiques. $2^{\mathrm{a}}$ edición, Grenoble. La pensée Sauvage, 2004.

BROUSSEAU, G. Le contrat Didactique: Le Milieu. Recherches en Didactiques des

Mathématiques, Grenoble, v. 9. n. 3, p. 309 -336, 1988.

BURRILL, G., BIEHLER, R. Fundamental statistical ideas in the school curriculum and in training teachers. In C. Batanero, G. Burrill, \& C. Reading (Eds.), Teaching statistics in school mathematicschallenges for teaching and teacher education-A joint ICMI/IASE Study: The 18th ICMI study $\mathrm{p}$. 57-69. 2011. Dordrecht: Springer.

EICHER, A.; VOGEL, M. Basic modelling of uncertainty: young students' mental models. ZDM Mathematics Education, Hamburgo, v. 44, p. 841 - 854, 2012.

KONOLD, C., Madden, S., Pollatset, A., Pfannkuch, M., Wild, C., Ziedins, I., et al. Conceptual challenges in coordinating theorical and data-centered estimates of probability. Mathematical thinking and learning, v. $13, \mathrm{n}^{\circ} 1 \& 2$, p. $68-86.2011$.

MÉNDEZ, T.; DÍAZ, 1. Acercamientos a la impredecibilidad en la enseñanza obligatoria. In: Acta latinoamericana de matemática educativa. México D.F. Comité Latinoamericano de Matemática Educativa. Colegio Mexicano de Matemática Educativa a.c. v. 27, 2014. p. 433 - 439.

MINEDUC. Bases Curriculares ciclo básico chileno - Programas de curso ciclo básico, 2012. Ministerio de educación de Colombia. Lineamientos curriculares colombianos. Bogotá 1998.

MEYER, P. Probabilidad y aplicaciones estadísticas. Mexico: Addison-Wesley Iberoamérica1986.

PERRIN-GLORIAN, M.; HERSANT, M. Milieu et contrat didactique, outils pour l'analyse de séquences ordinaires. Recherches en Didactiques des Mathématiques, Grenoble, v. 23, n. 2, p. 217 276, 2003.

PFANNKUCH, M.; WILD, CH.; PARSONAGE, R. A conceptual pathway to confidence intervals. ZDM Mathematics Education, Hamburgo, v. 44, n. 5, p. 899 - 911, agosto 2012.

SÁNCHEZ, E.; VALDEZ, J. La cuantificación del azar: una articulación de las definiciones subjetiva, frecuencial y clásica de probabilidad. Probabilidad Condicionada. Revista de Didáctica de la Estadística. Granada n. 1, p. 39 - 46, jun., 2013.

Imagen 1. Méndez, T. (2015). La jugada de futbol (croquis en grafito).

Imagen 2. La niña en la ventana. Fotografía (2014). Recuperado de http://1.bp.blogspot.com/Km2FucWcyLk/Tf-meBkGCtI/AAAAAAAAAHA/gvyl9a8dadk/s1600/2.jpg. 
Imagen 3: Mujer senior plantar una semilla. Fotografía (2014) recuperado de http://us.123rf.com/400wm/400/400/yuris010/yuris0101106/yuris010110600017/9849728-mujersenior-plantar-una-semilla-.

Imagen 4. Méndez, T. (2015). La puesta de sol (fotografía).

Submetido em Junho de 2015. Aprovado em Janeiro de 2016. 